\title{
Administration of four different doses of gabapentin reduces awakening from breakthrough pain and adverse effects in outpatients with neuropathic pain during the initial titration
}

\author{
Jong-Yeun Yang ${ }^{1}$, Won Il Lee ${ }^{1}$, Woo-Kyung Shin ${ }^{2}$, Cheul Hong Kim ${ }^{3}$, Seong-Wan Baik ${ }^{3}$, and \\ Kyung-Hoon $\mathrm{Kim}^{3}$
}

Department of Anesthesiology and Pain Medicine, ${ }^{1}$ Ajou University College of Medicine, Suwon, ${ }^{2}$ Seoul National University Hospital, Seoul, ${ }^{3}$ Pusan National University School of Medicine, Yangsan, Korea

Background: Gabapentin is a safe and well-tolerated anticonvulsant with a wide therapeutic index, and it is used for neuropathic pain. The aim of this study was to compare previous dosing methods with the administration of four different doses of gabapentin while maintaining the same maximum daily dose for the safe administration of high doses of the medication.

Methods: The subjects were outpatients with various neuropathic pain syndromes, with at least two of the following symptoms: allodynia, burning pain, shooting pain, or hyperalgesia. The TID group received equal doses of gabapentin 3 times per day, while the QID group received 4 different doses of gabapentin per day. The pain score, frequency of breakthrough pain (BTP), severity and the duration of pain, sleep disturbance due to nocturnal pain, and adverse effects were recorded each day.

Results: The average daily pain score and sleep disturbance were significantly reduced in the QID group between days 3 and 10 of the experiment. The adverse effects of the medication were also reduced in the QID group. However, the frequency of BTP and severity and duration of pain were not significantly different between two groups.

Conclusions: Administration of 4 different doses of gabapentin during the initial titration in outpatients with neuropathic pain resulted in a significant reduction in awakening from breakthrough pain and a reduction in the adverse effects of the medication. (Korean J Anesthesiol 2013; 65: 48-54)

Key Words: Ambulatory care, Drug administration schedule, Gabapentin, Neuropathic pain.

\footnotetext{
Received: July 30, 2012. Revised: 1st, October 19, 2012; 2nd, December 16, 2012; 3rd, January 2, 2013. Accepted: January 9, 2013.

Corresponding author: Kyung-Hoon Kim, M.D., Pain Clinic, Pusan National University Yangsan Hospital, Bumeu-ri, Mulgeum-eup, Yangsan 626-770, Korea. Tel: 82-55-360-2753, Fax: 82-55-360-2149, E-mail: pain@pusan.ac.kr

(c) This is an open-access article distributed under the terms of the Creative Commons Attribution Non-Commercial License (http:// creativecommons.org/licenses/by-nc/3.0/), which permits unrestricted non-commercial use, distribution, and reproduction in any medium, provided the original work is properly cited.
} 


\section{Introduction}

Gabapentin has a half-life of 5 to $7 \mathrm{~h}$ and is usually applied three times a day. During the period of initial titration, a regular dosing schedule of three times a day has two significant problems: breakthrough pain (BTP) caused by end-of-dose failure or predictable incidental BTP that in turn causes sleep disturbances at night or dawn and considerable adverse events such as dizziness, somnolence, and ataxia during the daytime.

There are significant differences between ambulatory outpatients and immobile inpatients in how gabapentin is administrated during the titration period. Immobile inpatients with neuropathic pain combined with or without somatic or visceral pain do not generally experience motion-related adverse events such as dizziness, nausea, and ataxia. This study focused on the difficulties of gabapentin titration in outpatients who are ambulatory and work during the daytime.

The standard gabapentin titration schedule is as follow: the starting dosage is $300 \mathrm{mg}$ and is increased by $300 \mathrm{mg} /$ day, over the first 3 days, up to a total of $900 \mathrm{mg} /$ day. This is increased by 400 $\mathrm{mg}$ /day from days 4 to 6 up to $1,200 \mathrm{mg}$ /day to maximize efficacy and delivered three times a day (TID). After 1 week of treatment, the dose is titrated up to $1,800 \mathrm{mg} /$ day. However, many ambulatory neuropathic patients have experienced common adverse events during the day and sleep deprivation from night pain. All intractable pain should be controlled from sleep deprivation due to night pain to pain during activity. The initiation dose and fast titration of gabapentin might be limited by intolerable side effects during day time in an ambulatory patient.

In present study, gabapentin was initiated and titrated at the same total daily dose as the standard schedule, but it was administered in unequal four times a day (QID). The two different schedules with the same total dose of gabapentin during the initiation and titration phase were compared in this study, from the view point of therapeutic and adverse effects.

\section{Materials and Methods}

This randomized study in ambulatory outpatient pain clinics was conducted over a period of 24 months. We obtained the approval of the Institutional Review Board, and written informed consent was obtained from the participants. All patients included in this study were required to have a definite diagnosis of neuropathic pain, made and confirmed by an experienced, practicing chronic pain specialist and based on the International Association for the Study of Pain Classification of Chronic Pain to support their clinical judgment [1]. In addition, all subjects were required to have at least two of the following nonspecific symptoms: allodynia, burning pain, shooting pain, or hyperalgesia.

All patients were routinely checked using laboratory examinations before administration of gabapentin. Patients were not allowed to drive or work that required attention whilst taking the medicine.

Patients were randomly divided into two groups, one group followed the conventional initiation and titration regimen (TID) and the other group followed the new regimen (QID), as Table 1. All patients were instructed to distribute the dosing interval as evenly as possible and to record the time of every dose. Every morning, the patients were asked to record the numeric rating score (NRS) for persistent pain, BTP, sleep disturbance due to pain, and adverse events during the previous day. The patients recorded their persistent pain in a daily dairy by using an 11-point scale with 0 as "no pain" and 10 as "worst imaginable pain". The period prevalence, intensity, and duration were recorded if BTP occurred. Sleep disturbance due to pain was

Table 1. Initial Titration Schedule

\begin{tabular}{|c|c|c|c|c|c|c|c|c|}
\hline \multirow{2}{*}{$\begin{array}{l}\text { Group } \\
\text { Time }\end{array}$} & \multicolumn{3}{|c|}{ TID } & \multirow{2}{*}{$\begin{array}{l}\text { Total daily } \\
\text { dose (mg) }\end{array}$} & \multicolumn{4}{|c|}{ QID } \\
\hline & $7 \mathrm{~A}$ & $1 \mathrm{~A}$ & $7 \mathrm{P}$ & & $7 \mathrm{~A}$ & $1 \mathrm{~A}$ & $7 \mathrm{P}$ & $11 \mathrm{P}$ \\
\hline \multicolumn{9}{|c|}{ First visit (Study day 0) } \\
\hline Day 1 & & & 300 & 300 & & & & 300 \\
\hline Day 2 & & 300 & 300 & 600 & 100 & 100 & 100 & 300 \\
\hline Day 3 & 300 & 300 & 300 & 900 & 200 & 200 & 200 & 300 \\
\hline \multicolumn{9}{|c|}{ Second visit (Study day 4) } \\
\hline Day 4-6 & 400 & 400 & 400 & 1200 & 300 & 300 & 300 & 300 \\
\hline \multicolumn{9}{|c|}{ Third visit (Study day 7) } \\
\hline Day 7-10 & 500 & 500 & 500 & 1500 & 300 & 300 & 300 & 600 \\
\hline \multicolumn{9}{|c|}{ Fourth visit (Study day 11) } \\
\hline Day 11-14 & 600 & 600 & 600 & 1800 & 400 & 400 & 400 & 600 \\
\hline \multicolumn{9}{|c|}{ Fifth visit (Study day 15) } \\
\hline Day 15 & 800 & 800 & 800 & 2400 & 600 & 600 & 600 & 600 \\
\hline
\end{tabular}

TID group received equal doses of gabapentin 3 times per day, QID group received 4 different doses of gabapentin per day. TID: three times a day, QID: four times a day. 
divided into 3 phases of sleep: induction, maintenance, and emergence. The time of adverse events was also recorded. All patients were also instructed to visit the pain clinic on study day 4, 7, 11, and 15 .

Exclusion criteria included previous treatment with gabapentin: a known creatinine clearance rate of less than $60 \mathrm{ml} /$ min or known renal impairment; clinically significant hepatic, respiratory, and hematological illnesses or unstable cardiovascular disease; significant neurological or psychiatric disorders unrelated to the causes of neuropathic pain; other severe pain that might impair the assessment of neuropathic pain; and illicit drug or alcohol abuse within the past year. Any patients who purposefully did not take gabapentin because of adverse effects or who unintentionally forgot to take it on time were excluded from this study.

Majority of the patients had already taken some form of medication for pain, such as non-steroidal anti-inflammatory drugs, opioids, tricyclic antidepressants, or benzodiazepines. However, the pain was refractory to medications in all cases. The patients were allowed to take pre-existing medication because discontinuation of those medications could aggravate the pain. However, there was no change to the type or dose of the pre-existing medication during the study.

Sufficient analgesia from gabapentin administration was

Table 2. Demographic Data, Classification of Neuropathy, and Previous Analgesic Administration

\begin{tabular}{lcc}
\hline & TID & QID \\
\hline Demographic data & & \\
Sex (M/F) & $251 / 249$ & $238 / 262$ \\
Age (yr) & $55.5 \pm 13.4$ & $58.5 \pm 15.1$ \\
Weight (kg) & $60.6 \pm 7.8$ & $61.7 \pm 8.3$ \\
Height (cm) & $160.7 \pm 5.3$ & $159.4 \pm 6.1$ \\
Neuropathic syndromes & 135 & \\
Radicular pain due to intervertebral & & 123 \\
$\quad$ disc herniation and spinal stenosis & 123 & 122 \\
Postherpetic neuralgia & 103 & 111 \\
Cancer-related neuropathy & 78 & 81 \\
Complex regional pain syndrome I \& II & 21 & 23 \\
Diabetic neuropathy & 16 & 15 \\
Phantom limb and stump pain & 13 & 14 \\
Post-mastectomy neuralgia & 8 & 9 \\
Intercostal neuralgia & 3 & 2 \\
Post-stroke neuralgia & & \\
Categories of analgesic drugs that & & \\
already taken & & \\
NSAIDs, acetaminophen, & 430 & 454 \\
$\quad$ and acetyl salicylate & & \\
Antidepressant & 134 & 120 \\
Benzodiazepines & 109 & 99 \\
Opioids and opioid-containing analgesics & 98 & 79 \\
\hline
\end{tabular}

TID group received equal doses of gabapentin 3 times per day, QID group received 4 different doses of gabapentin per day. TID: three times a day, QID: four times a day. defined as a daily NRS score less than 3, no sleep disturbance due to pain, and no BTP. If the patient demonstrated sufficient analgesia due to gabapentin to relieve neuropathic symptoms during the titration period of the study, the dose regimen of the last visit was maintained till the end of the study. Insufficient analgesia from gabapentin administration was defined as a daily NRS score of greater than 4, sleep disturbance due to pain, and more than 1 occurrence of BTP.

Unless otherwise indicated, all data were expressed as mean \pm standard deviation values. Demographic comparison between 2 groups was performed by Student's t-test. Statistical analysis of changes in pain score, BTP, and sleep disturbance was performed using repeated-measures analysis of variance. Adverse effects of 2 groups were compared by a chi-squared test. $P$ values less than 0.05 were considered to indicate statistical significance.

\section{Results}

Two patients were excluded from the TID group because of adverse effects, and 2 patients were excluded from the QID group because of unintentional mistakes. The treatment groups were well-matched at the baseline in terms of their sex, age, weight, height, and previous analgesic drug treatment. The neuropathic pain syndromes in this study were, in the order, as follow: radicular pain due to intervertebral disc herniation and spinal stenosis, post-herpetic neuralgia, cancer-related neuropathy, complex regional pain syndrome, diabetic neuropathy, phantom and stump pain, intercostal neuralgia, and post-stroke neuralgia (Table 2).

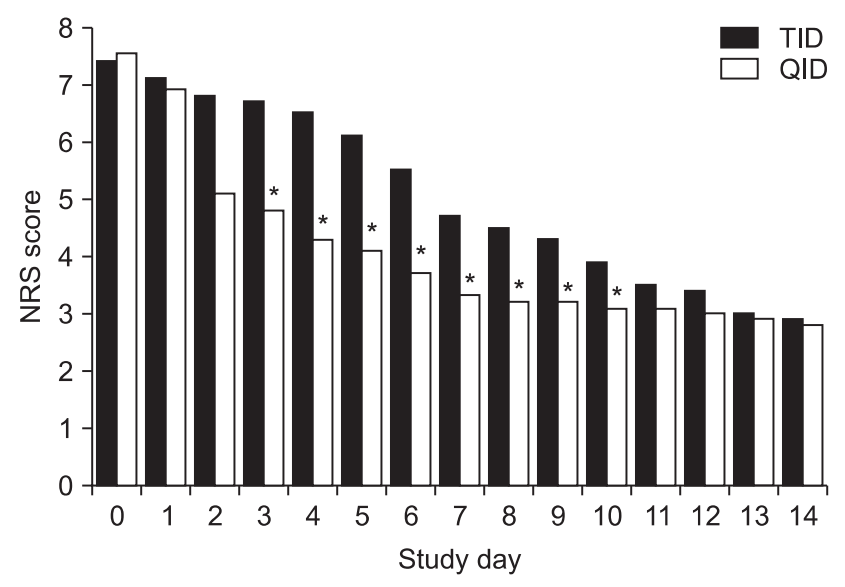

Fig. 1. The daily numeric rating scale (NRS) scores during the study period. The mean daily pain score between the baselines and the last day of the study did not show any significant differences between the 2 groups. However, the daily mean pain scores of the QID group* were significant lower scores than the scores from the TID group from study day 3 to 10 . 
Table 3. The Proportion of Sufficient Analgesia or Residual Pain from Gabapentin Administration Recorded on Each Visit Day

\begin{tabular}{|c|c|c|c|c|c|c|c|}
\hline Group & & TID & & & & QID & \\
\hline Visit day & $\begin{array}{l}\text { Sufficient } \\
\text { analgesia } \\
(\%)\end{array}$ & $\begin{array}{c}\text { Cumulative } \\
\text { sufficient } \\
\text { analgesia (\%) }\end{array}$ & $\begin{array}{l}\text { Residual } \\
\text { pain (\%) }\end{array}$ & $\begin{array}{l}\text { Total daily } \\
\text { dose (mg) }\end{array}$ & $\begin{array}{l}\text { Sufficient } \\
\text { analgesia } \\
(\%)\end{array}$ & $\begin{array}{c}\text { Cumulative } \\
\text { sufficient } \\
\text { analgesia (\%) }\end{array}$ & $\begin{array}{l}\text { Residual } \\
\text { pain (\%) }\end{array}$ \\
\hline Second visit (Study day 4) & $\begin{array}{c}26 \\
(5.2)\end{array}$ & $\begin{array}{c}26 \\
(5.2)\end{array}$ & $\begin{array}{c}474 \\
(94.8)\end{array}$ & 900 & $\begin{array}{c}29 \\
(5.8)\end{array}$ & $\begin{array}{c}29 \\
(5.8)\end{array}$ & $\begin{array}{c}471 \\
(94.2)\end{array}$ \\
\hline Third visit (Study day 7) & $\begin{array}{l}175 \\
(35)\end{array}$ & $\begin{array}{c}201 \\
(40.2)\end{array}$ & $\begin{array}{c}299 \\
(59.8)\end{array}$ & 1200 & $\begin{array}{c}184 \\
(36.8)\end{array}$ & $\begin{array}{c}213 \\
(42.6)\end{array}$ & $\begin{array}{c}287 \\
(57.4)\end{array}$ \\
\hline Fourth visit (Study day 11) & $\begin{array}{c}228 \\
(45.6)\end{array}$ & $\begin{array}{c}429 \\
(85.8)\end{array}$ & $\begin{array}{c}71 \\
(14.2)\end{array}$ & 1500 & $\begin{array}{c}231 \\
(46.2)\end{array}$ & $\begin{array}{c}444 \\
(88.8)\end{array}$ & $\begin{array}{c}56 \\
(11.2)\end{array}$ \\
\hline Fifth visit (Study day 15) & $\begin{array}{c}54 \\
(10.8)\end{array}$ & $\begin{array}{c}483 \\
(96.6)\end{array}$ & $\begin{array}{c}17 \\
(3.4)\end{array}$ & 1800 & $\begin{array}{c}45 \\
(9.0)\end{array}$ & $\begin{array}{c}489 \\
(97.8)\end{array}$ & $\begin{array}{c}11 \\
(2.2)\end{array}$ \\
\hline
\end{tabular}

TID group received equal doses of gabapentin 3 times per day, QID group received 4 different doses of gabapentin per day. TID: three times a day, QID: four times a day.

Table 4. Period Prevalence, Intensity, and Duration of Breakthrough Pain (BTP) Recorded on Each Visit Day

\begin{tabular}{|c|c|c|c|c|c|c|c|}
\hline Group & & TID & & & & QID & \\
\hline Visit day & $\begin{array}{c}\text { Period } \\
\text { prevalence } \\
(\%)\end{array}$ & $\begin{array}{c}\text { Mean } \\
\text { intensity }\end{array}$ & $\begin{array}{c}\text { Mean } \\
\text { duration } \\
\text { (Min) }\end{array}$ & $\begin{array}{l}\text { Total daily } \\
\text { dose (mg) }\end{array}$ & $\begin{array}{c}\text { Period } \\
\text { prevalence } \\
(\%)\end{array}$ & $\begin{array}{c}\text { Mean } \\
\text { intensity }\end{array}$ & $\begin{array}{c}\text { Mean } \\
\text { duration } \\
\text { (Min) }\end{array}$ \\
\hline Second visit (Study day 4) & $\begin{array}{c}421 \\
(84.2)\end{array}$ & 8.8 & 43.3 & 900 & $\begin{array}{c}399 \\
(79.8)\end{array}$ & 7.9 & 44.2 \\
\hline Third visit (Study day 7) & $\begin{array}{c}288 \\
(57.6)\end{array}$ & 8.4 & 35.7 & 1200 & $\begin{array}{c}265 \\
(53.0)\end{array}$ & 7.8 & 35.5 \\
\hline Fourth visit (Study day 11) & $\begin{array}{c}55 \\
(11.0)\end{array}$ & 8.3 & 29.0 & 1500 & $\begin{array}{c}44 \\
(8.8)\end{array}$ & 7.8 & 28.9 \\
\hline Fifth visit (Study day 15) & $\begin{array}{c}11 \\
(2.2)\end{array}$ & 7.6 & 22.9 & 1800 & $\begin{array}{c}9 \\
(1.8)\end{array}$ & 6.8 & 22.5 \\
\hline
\end{tabular}

Period prevalence: the number of patients who had BTP in each group at a given in time from previous visit to till last visit, Mean intensity: the sum of the numeric rating score (NRS)/period prevalence, Mean duration: the sum of duration of BTP/period prevalence.

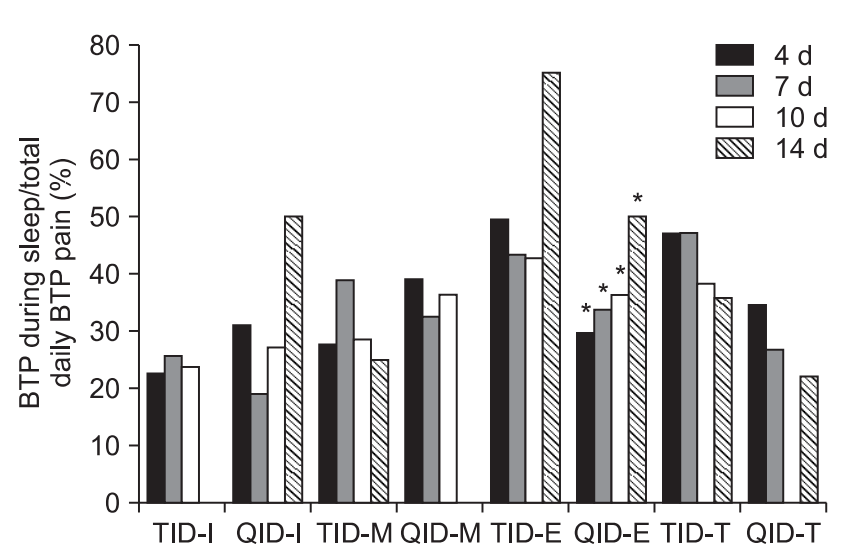

Fig. 2. The comparison of sleep disturbance due to pain classified as breakthrough pain (BTP) during sleep and the sleep phases of induction (I), maintenance $(\mathrm{M})$, and emergence $(\mathrm{E})$. *There were significantly frequent occurrences of BTP during the emergence sleep phase at 3 time serial periods in TID group following all visit days $(\mathrm{P}<0.05)$. However, there was no difference in BTP by the time serial between the TID and QID groups BTP during the emergence sleep phase was significantly reduced in QID group.
The baseline pain scores of the 2 groups were similar; these were 7.4 and 7.5 for the TID and QID groups, respectively. The mean daily pain scores from the baseline assessment to the final study day showed a significant decrease in both groups when compared with their retrospective baseline scores. However, compared to the TID group, the QID group showed statistically significant lower daily mean pain scores between the study day 3 and the study day 10. Changes in the mean daily pain score between the baseline and the last day of the study did not show a significant difference between 2 groups (Fig. 1).

The sufficient total daily dose of gabapentin started from $900 \mathrm{mg}$, at study day 3. They were 26 patients in TID group, and 29 patients in QID group. There were 17 in the TID and 11 patients QID group, who reported residual pain from gabapentin administration at study day 15 . However, there was no statistically difference of patient satisfaction of sufficient analgesia (Table 3).

There was no difference between the groups with respect to the prevalence, mean intensity, and mean duration of BTP (Table 4). 


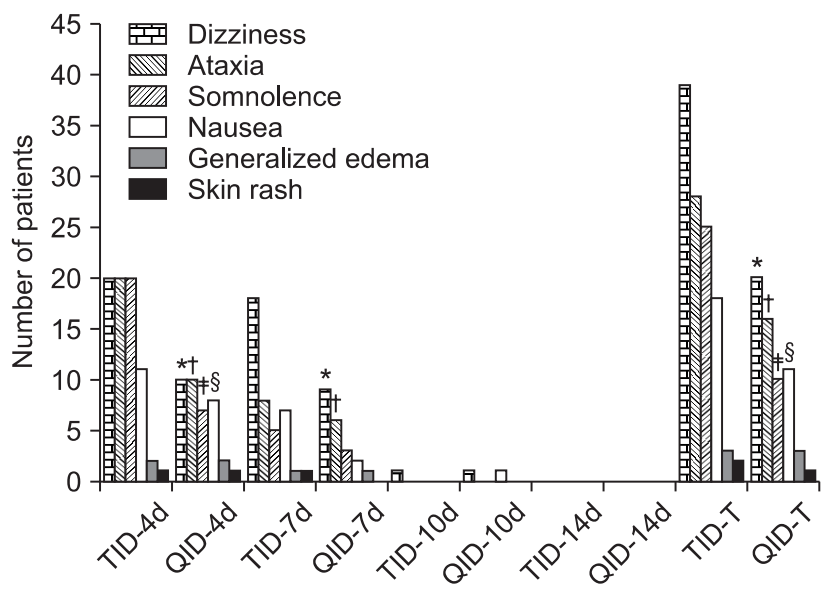

Fig. 3. Adverse effects. ${ }^{*,+, \neq, \S}$ Indicates that that there were statistically differences $(P<0.05)$ between TID and QID groups in the number of instances of dizziness, ataxia, somnolence, and nausea reported on second visits. ${ }^{*}{ }^{\dagger}$ Indicates that there were statistically differences $(\mathrm{P}<0.05)$ between TID and QID groups in the number of instances of dizziness and ataxia reported on second and third visits. ${ }^{*,+, \neq, 8}$ Indicates that that there were statistically differences $(\mathrm{P}<0.05)$ between TID and QID groups in the total number of instances of dizziness, ataxia, somnolence, and nausea reported during the whole study.

There were significantly frequent occurrences of BTP during the emergence sleep phase at 3 time serial periods in TID group following all visit days. However, there was no difference in BTP by the time serial between the TID and QID groups (Fig. 2).

Adverse effects due to gabapentin administration, including dizziness, ataxia, somnolence, and nausea were significant lower in the QID group than in the TID group during the 14 days of the study (Fig. 3).

\section{Discussion}

It appears that gabapentin should be started at $300 \mathrm{mg}$ once a day (quaque die [QD]) and titrated as necessary over 4 weeks to a maximum total daily dose of $3,600 \mathrm{mg}$ or until intolerable adverse effects occur. It is started at a dose of $900 \mathrm{mg} /$ day just like $300 \mathrm{mg}$ /day on day $1,600 \mathrm{mg} /$ day on day 2 , and $900 \mathrm{mg}$ /day on day 3. Additional titration up to $1,800 \mathrm{mg} /$ day is recommended for greater efficacy [2]. At doses of 1,800 to $3,600 \mathrm{mg} /$ day, gabapentin was effective and well-tolerated in the treatment of adults with neuropathic pain [3]. However, adverse events such as drowsiness, sedation, dizziness, malaise, and lassitude were frequently reported during the titration phase and were also the most common reasons for discontinuing gabapentin $[4,5]$.

Gabapentin has a half-life of 5 to $7 \mathrm{~h}$, and maximum plasma concentrations are reached after approximately $3.2 \mathrm{~h}$ following oral ingestion. There is a difference between the strict $8 \mathrm{~h}$ dosing and the less restrictive TID. According to dietary schedule and sleeping time, it is difficult for patients with neuropathic pain to strictly take gabapentin every $8 \mathrm{~h}$. After ingestion of drugs including gabapentin in the evening around 7 to 8 o'clock following dinner, the next medication is usually taken in the morning around 7 to 8 oclock following breakfast, according to the TID regimen. The drug administration interval is therefore approximately $12 \mathrm{~h}$. Even if the last medication is delayed until just before sleep, the administration interval becomes at least 7 to $8 \mathrm{~h}$. However, it is not easy to keep taking medication three or four times in a day. If patients feel little pain in the evening, it is easy to forget to take medication at night before sleep. This will be the difficulty in the QID titration method on a clinical basis.

The 3 known basic steps for pain management are first to remove pain at night, second to remove pain in bed, and finally to remove pain during activity. The first goal, to remove pain at night, is usually interrupted by BTP rather than by persistent pain during the titration period. While there is no clear consensus regarding its definition, a common working definition for BTP is an abrupt, short lived and intense pain that can "breakthrough" the around-the-clock analgesia that controls persistent pain [6]. On the basis of the information obtained from medical histories and physical examinations, the BTP experienced by most patients can be categorized as one of three subtypes: incidental; idiopathic or spontaneous; and end-of-dose. The incidental or spontaneous subtype is the most common, accounting for about half of BTP episodes. Incidental BTP can be further divided into two categories: predictable and unpredictable. Predictable BTP is directly related to musculoskeletal movements, such as coughing or turning over in bed, and unpredictable BTP is the result of contractions or spasms of visceral smooth muscles, such as with bowel or bladder spasms [7]. The prevalence of neuropathic BTP is more common in the initial titration phase than in the maintenance phase of gabapentin administration because of predictable incidental BTP episodes or end-of-dose failure. Metastatic cancer pain has all 3 types of BTP etiology, including somatic, visceral, and/or neuropathic origin. In this study, it was difficult to recognize and differentiate the 3 types of BTP characteristics because the participants were outpatients. However, it was possible for patients to record the prevalence of sleep disturbance due to night pain by the classification of BTP during the following sleep phases: induction, maintenance, and emergence. Even though there was no difference in the prevalence, intensity, and duration of BTP between the 2 groups, the number of patients who experienced emergence from sleep due to pain much larger than the number of patients who experienced sleep induction or difficulty in sleep maintenance in this study. This means that during the initiation and titration period, it is important to control BTP, an abrupt, short lived and intense pain, rather than persistent pain, which is more problematic in the maintenance period. Majority of patients in both groups, from 64.7 to $96.3 \%$, who experienced persistent 
pain, also complained of BTP. It seems that it is difficult to provide patients who experienced BTP with sufficient analgesia from gabapentin.

High doses of gabapentin may be tolerable because most of the drug is excreted unabsorbed. However, higher doses and faster titration schedules have caused considerable side effects such as somnolence, asthenia, weight gain, ataxia, vertigo, headache, and nausea [8]. "Start low, go slow" is frequently used as prudent advice, but there is high inter-patient variability in absorption and dose-dependent absorption, resulting in confusion about how to titrate gabapentin [9].

Following oral administration, gabapentin is rapidly and reliably absorbed from the small intestine and. This occurs via a specific, though unidentified, transport mechanism that becomes saturated at higher doses [10]. This has the effect of reducing bioavailability at higher doses. The bioavailability of a $300 \mathrm{mg}$ dose is approximately $60 \%$, for $600 \mathrm{mg}$ it is $40 \%$, and only $35 \%$ for $1600 \mathrm{mg}$ administrated three times daily [11]. In addition, the bioavailability may be significantly increased by using QID instead of TID dosing, depending upon dose level [12].

In one study, elderly gabapentin-naïve subjects benefited a moderate pain relief with minimal side effects at the first three days of treatment, regardless whether they received 200, 400 or $600 \mathrm{mg} /$ day of gabapentin. The authors suggested that 600 $\mathrm{mg} /$ day gabapentin could be a safe and effective starting dose for patients with post-herpetic neuralgia [13]. Older patients did not experience any more adverse events related to the central nervous system than younger patients, suggesting that gabapentin has a good tolerability profile in older patients [14]. Dizziness and somnolence were mild to moderate in intensity and mostly transient, and occurred during the titration phase. These symptoms were the main cause of the withdrawal of gabapentin [2].

In order to reduce the prevalence of withdrawal symptoms and recurrence of pain during the discontinuation of gabapentin after normalizing the previous pain threshold and the previous pain response due to neuropathy, we tapered the reduction of gabapentin doses in the reverse order to the study design [15]. However, it seemed that there was no difference in therapeutic and adverse effects between 2 groups after the administration of gabapentin for 10 days.

The sufficient total daily dose of gabapentin started at $900 \mathrm{mg}$ at study day 3. The cumulative proportions of patients reporting sufficient analgesia from gabapentin administration in both groups was over 5, 40, 80 and $90 \%$ at a total daily dose of 900 , $1,200,1,500$, and $1,800 \mathrm{mg}$, respectively. This means that there was no need to increase the dose of gabapentin over $1,800 \mathrm{mg}$ in more than $90 \%$ patients with neuropathic pain. However, there were $3.4 \%$ in the TID group and $2.2 \%$ in the QID group were non-responders were administrated gabapentin up to $3600 \mathrm{mg}$, and they also have received neural blockades and spinal cord stimulation after the study.

When comparing BTP during sleep and sleep disturbance due to pain at the sleep stages of induction, maintenance, and emergence, there were significant statistically difference in BTP during the sleep emergence phase at 3 time points in the TID group. We hypothesize that the occurrence of BTP at sleep emergence phase is due to end-of-dose failure of gabapentin at night or dawn. It is possible that the end-of-dose failure could occur more frequently in the TID group.

Regardless of disease entities, gabapentin might be a good at positive treatment for neuropathic pain symptoms such as spontaneous pain, paresthesia, dysesthesia, allodynia, hyperalgesia, and hyperpathia on the basis of the proposed mechanisms of ectopic activity and peripheral and central sensitization, but might not be a good treatment for negative neuropathic pain symptoms due to axon/neuron loss combined with sensory deficits [16].

The limitation of our study was that therapeutic drug monitoring of gabapentin in outpatients was not performed. It would be useful to obtain the exact blood concentration of gabapentin due to the different administration methods. It was also difficult to differentiate neuropathic BTP in patients with somatic and visceral pain.

In conclusion, before titration of gabapentin, especially from study day 3 to 10 , adding the administration of gabapentin at night may reduce awakening from BTP caused by end-of-dose failure and spontaneous pain and also reduce adverse effects during daytime caused by reduced administration of doses. When comparing these two different schedules that have the same total administration dose of gabapentin during the initiation and titration period from the view point of therapeutic and adverse effects, administration in an unequally divided QID manner had some merits with lower pain scores from study day 3 to 10 and fewer adverse effects in ambulatory patients during the study period.

\section{References}

1. Merskey H, Bogduk N. Classification of chronic pain: descriptions of chronic pain syndromes and definitions of pain terms. 2nd ed. Seattle, IASP Press. 1994, pp 1-240. 
2. Serpell MG. Gabapentin in neuropathic pain syndromes: a randomised, double-blind, placebo-controlled trial. Pain 2002; 99: 557-66.

3. Backonja M, Glanzman RL. Gabapentin dosing for neuropathic pain: evidence from randomized, placebo-controlled clinical trials. Clin Ther 2003; 25: 81-104.

4. Rice AS, Maton S. Gabapentin in postherpetic neuralgia: a randomised, double blind, placebo controlled study. Pain 2001; 94: 215-24.

5. Wilton LV, Shakir S. A postmarketing surveillance study of gabapentin as add-on therapy for 3,100 patients in England. Epilepsia $2002 ; 43: 983-92$.

6. Payne R. Introduction: The scope of breakthrough pain in clinical practice. Pain Med 2007; 8: S1-2.

7. Payne R. Recognition and diagnosis of breakthrough pain. Pain Med 2007; 8 Suppl 1: S3-7.

8. Morrell MJ, McLean MJ, Willmore LJ, Privitera MD, Faught RE, Holmes GL, et al. Efficacy of gabapentin as adjunctive therapy in a large, multicenter study. The Steps Study Group. Seizure 2000; 9: 241-8.

9. Gidal BE, Radulovic LL, Kruger S, Rutecki P, Pitterle M, Bockbrader HN. Inter- and intra-subject variability in gabapentin absorption and absolute bioavailability. Epilepsy Res 2000; 40: 123-7.

10. Elwes RD, Binnie CD. Clinical pharmacokinetics of newer antiepileptic drugs. Lamotrigine, vigabatrin, gabapentin and oxcarbazepine. Clin Pharmacokinet 1996; 30: 403-15.

11. Vollmer KO, Anhut H, Thomann P, Wagner F, Jahncken D. Pharmacokinetic model and absolute bioavailability of the new anticonvulsant gabapentin. Adv epileptol 1989; 17: 209-11.

12. Gidal BE, DeCerce J, Bockbrader HN, Gonzalez J, Kruger S, Pitterle ME, et al. Gabapentin bioavailability: effect of dose and frequency of administration in adult patients with epilepsy. Epilepsy Res 1998; 31: 91-9.

13. Jean WH, Wu CC, Mok MS, Sun WZ. Starting dose of gabapentin for patients with post-herpetic neuralgia--a dose-response study. Acta Anaesthesiol Taiwan 2005; 43: 73-7.

14. Rowbotham M, Harden N, Stacey B, Bernstein P, Magnus-Miller L. Gabapentin for the treatment of postherpetic neuralgia: a randomized controlled trial. JAMA 1998; 280: 1837-42.

15. Norton JW. Gabapentin withdrawal syndrome. Clin Neuropharmacol 2001; 24: 245-6.

16. Woolf CJ. Dissecting out mechanisms responsible for peripheral neuropathic pain: implications for diagnosis and therapy. Life Sci 2004; 74: 260510. 